\title{
PREDICTION OF ROCK PRESSURE EFFECTS IN MINE WORKINGS IN THE ZONE OF LONGWALL FACE INFLUENCE
}

\author{
Didenko, $M$. \\ Candidate of Science, associate professor of Mining sub faculty of \\ Volodymyr Dahl East Ukrainian National University, Severodonetsk, \\ Ukraine
}

When dredging flat coal seams using a pillar system of development, before the approach to the face, the preparatory workings go through three characteristic periods of their existence:

I - in the zone of influence of the face;

II - outside the zone of influence of the face;

III - in the zone of temporary abutment pressure in front of the longwall face.

Mine research indicates significant features of the rock pressure effect in these zones. To study the distribution of stresses around the mine working developed in the zone of temporary abutment pressure of the moving longwall, a three-dimensional elastic numerical problem was solved by the finite element method.

The object of the study was a rock mass in the vicinity of a single longwall developing with a pillar system a flat coal seam.

The subject of research is the stress-strain state of the rocks around the mine working in the zone of temporary abutment pressure of the longwall, depending on the type of roof (easily-, medium- and hard-to-break) and the length of the cantilever of suspended rocks (0-5 $\mathrm{m}$ for easy-breaking roof; $0-20 \mathrm{~m}$ for medium-breaking and 0-35 $\mathrm{m}$ for hard-breaking).

The study and prediction of geomechanical processes that is realized around the longwall face will significantly solve the problem of the stability of mine workings.

\section{Introduction}

As a result of the coal production in the undermined stratum, complex and largely random geomechanical processes occur. Part of the rocks, located directly above the developed space, is deformed and collapses, losing contact with the rock mass. The rock layers lying above bend over the worked out space and play the role of rock slabs redistributing the load from the overlying stratum.

Regardless of the technology of coal mining, the movement of the longwall face and the periodic process of hovering and collapse of suspended rocks change the stress-strain state of the formation and surrounding rocks. The stress distribution around the longwall, first 
of all, depends on the step of the main roof sedimentation and the length of the hanging rock console, reflecting the rhythmicity of the processes of coal extraction.

Currently used methods for controlling geomechanical processes in time of coal production have exhausted their capabilities and do not guarantee the safety of mining. A further increase in the efficiency of coal production and ensuring the reliability of the mine workings is possible only on the basis of the results of modern fundamental studies of the mechanism of formation of rock pressure around the mine workings and the laws of its effect [1].

In this case, the main tasks that need to be solved are determining the size of the zone of abutment pressure, studying the distribution of stresses in the abutment zone, evaluating additional displacements of the rock formation contour and loads on the lining. The solution to these problems is based, first of all, on the analysis of the stress-strain state of the rock mass around the face during the excavation of a flat coal seam by a long face with a complete collapse of the roof.

Currently, numerical methods for solving geomechanical problems, in particular, the finite element method (FEM) [2, etc.], which allows to implement the principles of simulation modeling of geomechanical processes, are most relevant to the specific task of assessing the properties of the medium under study and the mechanical state of the rock mass near the longwall face on a PC.

\section{The volumetric numerical problem of the distribution of stresses in the rock mass around a single longwall face}

The stress distribution in the zone of temporary abutmrnt pressure was studied in order to establish the dimensionless function of the influence of the longwall face on the stress state of the rocks around the mine working, which is supposed to be used as a multiplier to the components of the initial stress field when studying the effects of rock pressure in the mine on a flat model taking into account the fracture zone rocks formed at the time of the beginning of the coal extraction. Therefore, the problem was solved in an elastic setting for a transversely isotropic massif without taking into account the bedding and fracture of the roof rocks. On the one hand, such idealization leads to a simplification of the mathematical model, and on the other hand, unaccounted 
characteristics increase the stresses, which go into the margin of safety and are acceptable at the initial stage of research.

The mathematical model represents a prismatic fragment of the rock mass. The fragment sizes are taken taking into account the angles of movement of the undermined rock mass. The height of the model is $780 \mathrm{~m}$, the width is $448 \mathrm{~m}$. The size of the model in the direction of movement of the longwall face is $310 \mathrm{~m}$. Due to the symmetry, the design model includes half of the longwall.

A coal seam with a thickness of $1 \mathrm{~m}$ lies at a depth of $650 \mathrm{~m}$ from the earth's surface to the soil of the seam. A working face with a half length of longwakk $129 \mathrm{~m}$ is located in the middle of the model, while the distance from the face to the end face of the fragment in front of the longwall is taken to be $100 \mathrm{~m}$, the distance from the worked out space to the side face is $319 \mathrm{~m}$, the width of the working space of the longwall is $5 \mathrm{~m}$; the length of the cantilever of suspended rocks varies from 0 to $35 \mathrm{~m}$, and the length of the worked out space where the collapse of the rocks was realized and their compaction occurs is $170 \mathrm{~m}$.

The geological structure of the rock mass is selected in relation to the mines of Donbass. The cross-sectional shape of the mine has been adopted rectangular with a lower blasting of rocks, the method of protecting the preparatory mine from the mined-out side is a strip of prefabricated reinforced concrete blocks (БЖБТ), the mine working is reused, therefore it is maintained behind the longwall.

The calculated fragment is loaded with its own weight of rocks and coal under the following boundary conditions: on the lower surface of the model, there are no vertical or horizontal movements; along the lateral and end vertical surfaces of the model, there are no horizontal components of displacements and there are vertical as well as tangential displacements.

The modeling in the settlement schemes of the collapsed rock zone of the worked out space was based on the well-known assumption of the three-zonal nature of the rock displacement along the vertical of the undermined massif and the gradual compaction of the rocks of the random collapse zone (horizontal), which was limited by the size of the layer corresponding to the thickness of the formation. Based on the generated model, a calculation was implemented using the «Лира-9» computer software package $[3,4]$. In total, 12 variants of the numerical problem were solved to determine the initial stress field, the stress field 
after the preparatory development of a rectangular cross section, as well as the stress-strain state of the rock mass during the coal production.

\section{Function of the influence of the longwall face on the stress dis- tribution in the zone of temporary abutment pressure}

The studies showed that an adequate forecast of the effects of rock pressure in the mine working, which is exposed to the longwall influence, when modeling on an elastic model of the massif is impossible.

The development of a numerical spatial elastoplastic model taking into account the extreme deformation of rocks is a separate and very difficult task. The use of a flat numerical model in the zone of temporary reference pressure is incorrect, since the longitudinal strain is $\varepsilon_{y} \neq 0$. However, with practical accuracy it is possible to reproduce the patterns of deformation of the rock mass around the preparatory development in the zone of temporary abutment pressure of the longwall by replacing the spatial problem with a series of successively solved plane problems when the initial and boundary conditions at each subsequent step are set based on the solution of the problem at the previous step.

To maximize the display of processes of stress redistribution and displacement of a layered rock mass in the vicinity of a mine working, the following factors are taken into account: an alternating field of stress distribution at various distances to the longwall face; the real structure of the layered carbon-bearing stratum with heterogeneous mechanical characteristics and broken contacts between the layers; complete rock deformation diagram; joint deformation of the array and lining.

The correction of boundary conditions in the zone of temporary longwall abutment pressure is performed by multiplying the stresses by the concentration coefficient $k_{\sigma}$. The dependence of this coefficient on the distance to the longwall face is a function of the influence of the face. 


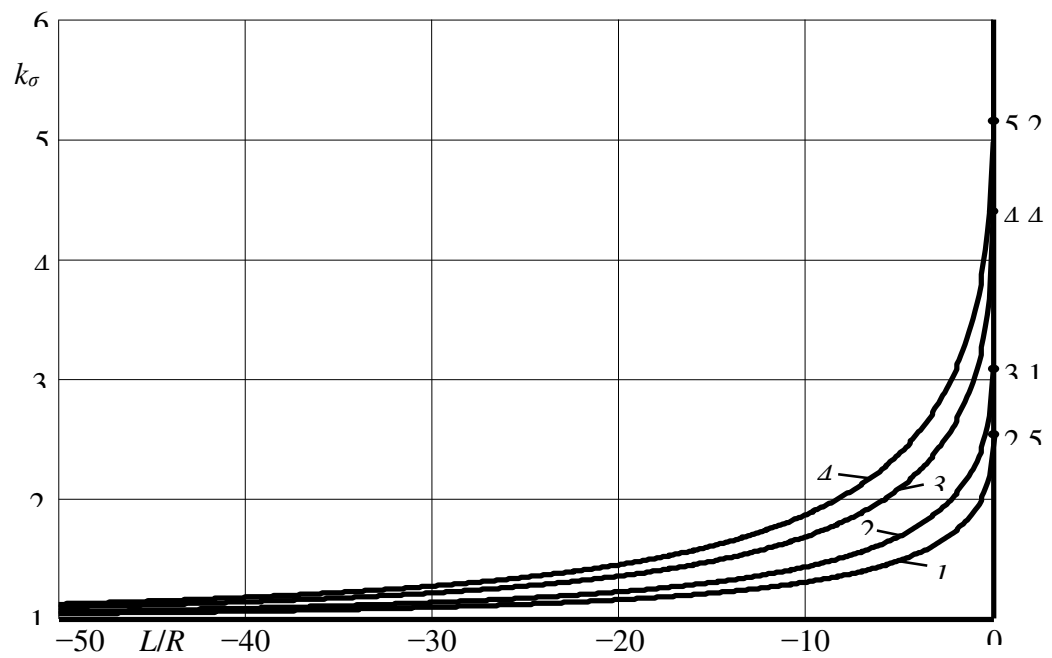

Fig. 1. The influence function of the longwall face in the zone of temporary abutment pressure at $l_{\kappa}=1(1) ; l_{\kappa}=2(2) ; l_{\kappa}=5(3) ; l_{\kappa}=8(4)$

The type of this function was determined by calculating the threedimensional elastic problem. Processing the results of the least squares simulation gives the following form of function

$$
k_{\sigma}=1+\frac{b}{\exp (0,5 \cdot \sqrt{-L / R})}
$$

$L$ is the distance to the longwall face,

$R$ is the reduced radius of the mine working.

The value of coefficient $b$ depends on the type of roof and the length of the cantilever of suspended rocks $l_{\kappa}$, reduced to a dimensionless form:

$$
l_{k}=1+l_{3} / l_{p}
$$

$l_{p}$ is the width of the working space of the longwall, m;

$l_{3}$ is the length of the cantilever of suspended rocks (for an easily collapsed roof it is 0 to $5 \mathrm{~m}$, for a medium collapsed 2 to $20 \mathrm{~m}$, for a hard collapsed 4.5 to $35 \mathrm{~m}$ ).

The value of coefficient $b$ is approximated with a theoretical correlation ratio of 0.99 , a power function

$$
b=1,503 \cdot l_{k}^{0,528}
$$


Given formula (3), dependence (1) can be written as

$$
k_{\sigma}=1+\frac{1,5 \cdot \sqrt{l_{\kappa}}}{\exp (0,5 \cdot \sqrt{-L / R})}
$$

An analysis of the function (4) for various values of the relative length of the hanging rocks is presented in Fig. 1. On the face line, i.e. at $L=0$, the range of variation of the stress concentration coefficient is from $k_{\sigma}=2.5$ for an easily collapsible roof to $k_{\sigma}=5.24$ for an hard collapsed roof.

\section{Prediction of rock pressure effects in the mine working during its development}

To predict the rock pressure effects, a specially developed program was used to obtain a stress field around a mine working on a flat model of the rock mass taking into account the extreme deformation of the rocks. The solution to the problem is performed on the same network of finite elements for the three stages of development:

- in the zone of influence of the mine working face during its implementation;

- outside the zone of influence of longwall, i.e. after the formation of a stationary stress field before the impact of the longwall face;

- in the zone of the longwall temporary abutment pressure.

At the construction stage of the mine working, a drift of a rectangular cross section was simulated using a tunneling machine on a coal seam with a lower blasting of rocks. The geomechanical conditions of the drift construction corresponded to the volumetric problem considered above. The forces specified along the periphery of the computational domain are selected so that the initial stress state, which is characteristic of the gravitational stress field in an undisturbed array, is correctly reproduced in the planar system under study.

The computational domain consists of 10931 triangular elements and 5543 nodes. To simplify the calculation, the selected area of the array was considered without taking into account the dead weight of the rocks. Along the lower boundary of the calculated fragment, knot displacements were forbidden.

To simulate the initial field of gravitational stresses along the external contour of the model, concentrated forces were applied corresponding to the acting stresses in the volumetric problem. At various distances from the bottom, the external load was corrected by the working 492 
face impact function [5]. The action of the lining on the rocks along the output circuit at this stage of the calculation was not taken into account. For all types of rocks and working sections, a unified model of elastoplastic deformation of rocks was adopted taking into account a linear decrease in rock resistance beyond the ultimate strength $\left(\varepsilon_{p}=3 \varepsilon_{y}, \sigma_{o}=\right.$ $\left.0.1 \sigma_{c}\right)$.

According to the calculation results, the maximum principal stresses $\sigma_{l}$ are concentrated in the sides, as well as near the lower and upper corners of the mine working, and the minimum stresses $\sigma_{3}$ are in the mine roof. Already at a distance of $1.6 \mathrm{~m}$ from the face of the mine (before the installation of the lining), an inelastic deformation zone was formed along almost the entire contour of the mine working. The area occupied by the destroyed elements in the plane of the model was $90 \%$ of the cross-sectional area of the mine working. At a distance of $188 \mathrm{~m}$ from the face, it amounted to $120 \%$, which is, increased 1.35 times. The greatest increase is observed in the soil of mine working. The maximum depth of the fracture zone is not founded in the coal seam, but under it.

Prediction of rock pressure effects while maintaining mine working outside the zone of influence of longwall face

After stabilization of the stress distribution field, deformation of the rocks around the mine takes place at a constant load, but with varying long-term rock strength, which was set in the layers of finite elements surrounding the mine working in accordance with the expression

$$
\sigma_{c}(r)=\sigma_{c} \cdot\left(1-a \cdot r^{-n}\right)
$$

where $r$ is the radial coordinate referred to the reduced radius of the mine;

$a, n$ are dimensionless approximation parameters taken equal to $a=0.35, n=3$ ).

The distribution of stresses around the mine outside the zone of influence of working and longwall faces is fully consistent with the distribution of stresses during mine working development. However, as a result of a decrease in the rock strength over time, the relative area of the destroyed elements reached $130 \%$, i.e. the area of the destruction zone increased 1.1 times. Moreover, the growth of the destruction zone is observed in all directions, and the greatest increase occurs in the soil 
of the mine working. Consequently, soil heap will occur in the mine working.

Prediction of rock pressure effects while maintaining mine working in the zone of temporary abutment pressure

Prediction of rock pressure effects in the zone of influence of longwall face is performed taking into account the zone of rock destruction around the mine working, which was formed by the time the mine workins occurs into the zone of temporary abutment pressure. Two calculation options have been performed: for an easily collapsible roof (the minimum cantilever of suspended rocks) and for a hard-tocollapse roof (maximum cantilever of a suspended rock).

When the roof collapses with the approaching face near the working face, the appearance of the stress field is maintained, however, the values of both compressive and tensile (modulo) stresses increase, with the maximum principal stresses $\sigma_{l}$ increasing 2.36 times and the minimum $\sigma_{3}$ increasing 2.25 times. As a result of the general increase in stresses, the relative area of the fracture zone also increases, reaching $210 \%$ on the longwall face, which is 1.6 times the size of the zone of inelastic deformations outside the zone of influence of the longwall.

With a hard-to-collapse roof in the zone of temporary reference pressure, the maximum principal stresses $\sigma_{l}$ increase by 3.7 times, and the minimum principal stresses $\sigma_{3}$ increase by 3.9 times. At the same time, the relative area of the fracture zone on the longwall face line was $250 \%$, which is 1.9 times larger than the size of the zone of inelastic deformations outside the zone of influence of the longwall face.

The range of changes in the relative area of the destruction zone with an easily collapsible roof with a minimum cantilever and a hardto-collapse roof with a maximum cantilever was $210-250 \%$, i.e. the area of rock destruction in the most difficult conditions of maintaining the development is 1.2 times higher than the same indicator for the lightest mining and geological conditions.

\section{Prediction of rock pressure effects when maintaining a mine working with a spacer support}

Prediction of rock pressure effects around a timbered mine working taking into account the active spacer support was made for the same conditions. In the development of a rectangular cross-sectional shape, the effect of adaptive support was simulated with a two-stage effect on rock outcrop due to the expansion of racks between the soil and the 
roof of the mine $[6,7]$. The effect of the compressive force on the destroyed rocks of the zone of inelastic deformations of $P=560 \mathrm{kN}$ was simulated, as well as the support resistance in the roof $P_{k p}=435 \mathrm{kN} / \mathrm{m}$ and in the sides $P_{\sigma}=200 \mathrm{kN} / \mathrm{m}$.

Calculation of the bearing capacity of the rock mass - support system in the area of the extreme deformation of the rocks, the depth of the rock compaction zone, the averaged coefficient of fracture voidness of the rocks, strength and deformation parameters of the finite elements within the compaction zone was carried out according to the method described in [8].

The depth of the compaction zone in the roof and sides of the mine was taken to be $1.25 \mathrm{~m}$, and the values of the average coefficient of fracture voidness of the rocks at various distances to the bottom were:

$$
1.6 \mathrm{~m}-k_{m p}=0.0133 ; 8 \mathrm{~m}-k_{m p}=0.0136 ; 20 \mathrm{~m}-k_{m p}=0.0147 \text {; }
$$

$188 \mathrm{~m}-k_{m p}=0.0154$.

To simulate the effect of the sealing force on the properties of the marginal rocks within the zone of influence of the lining (the roof and the working sides at a distance of $1.25 \mathrm{~m}$ from the contour), 3 layers were selected for which the residual strength and softening strains were assigned as follows. In the first layer (0-0.25 $\mathrm{m}$ from the contour)

$$
\begin{gathered}
\varepsilon_{p}=15 \varepsilon_{y}, \sigma_{o}=0.9 \sigma_{l} ; \text { in the second }(0.25-0.75 \mathrm{~m} \text { from the circuit }) \\
\varepsilon_{p}=10 \varepsilon_{y}, \sigma_{o}=0.75 \sigma_{l} ; \text { in the third }(0.75-1.25 \mathrm{~m} \text { from the circuit }) \\
\varepsilon_{p}=6.6 \varepsilon_{y}, \sigma_{o}=0.5 \sigma_{1} . \text { For all other layers and types of rocks } \\
\varepsilon_{p}=3 \varepsilon_{y}, \sigma_{o}=0.1 \sigma_{l} .
\end{gathered}
$$

In fig. 2 and fig. 3 it is shown the configurations of rock destruction zones around a mine working with easily collapsible and hard-tocollapse roofs in the zone of influence of longwall face during compaction of the destroyed rocks and expansion of the lining at various distances from the longwall face line. 

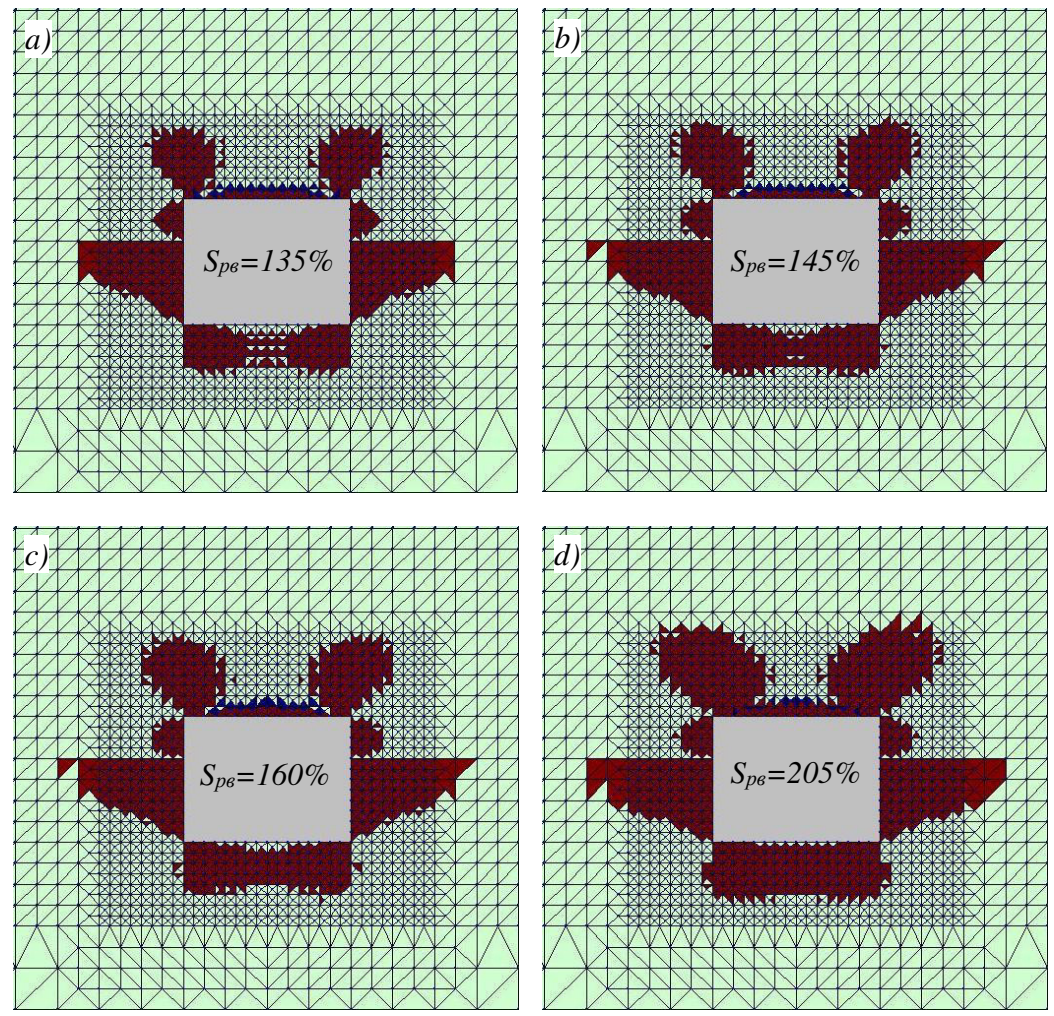

- tensile stress fracture;

- compressive stress fracture;

- undestructed elements

Fig. 2. The configurations of rock destruction zones around a mine working with easily collapsible roof in the zone of influence of longwall face during compaction of the destroyed rocks and expansion of the lining at various distances from the longwall face line: $20 \mathrm{~m}(a), 10 \mathrm{~m}(b), 5 \mathrm{~m}(c), 0 \mathrm{~m}(d)$ 

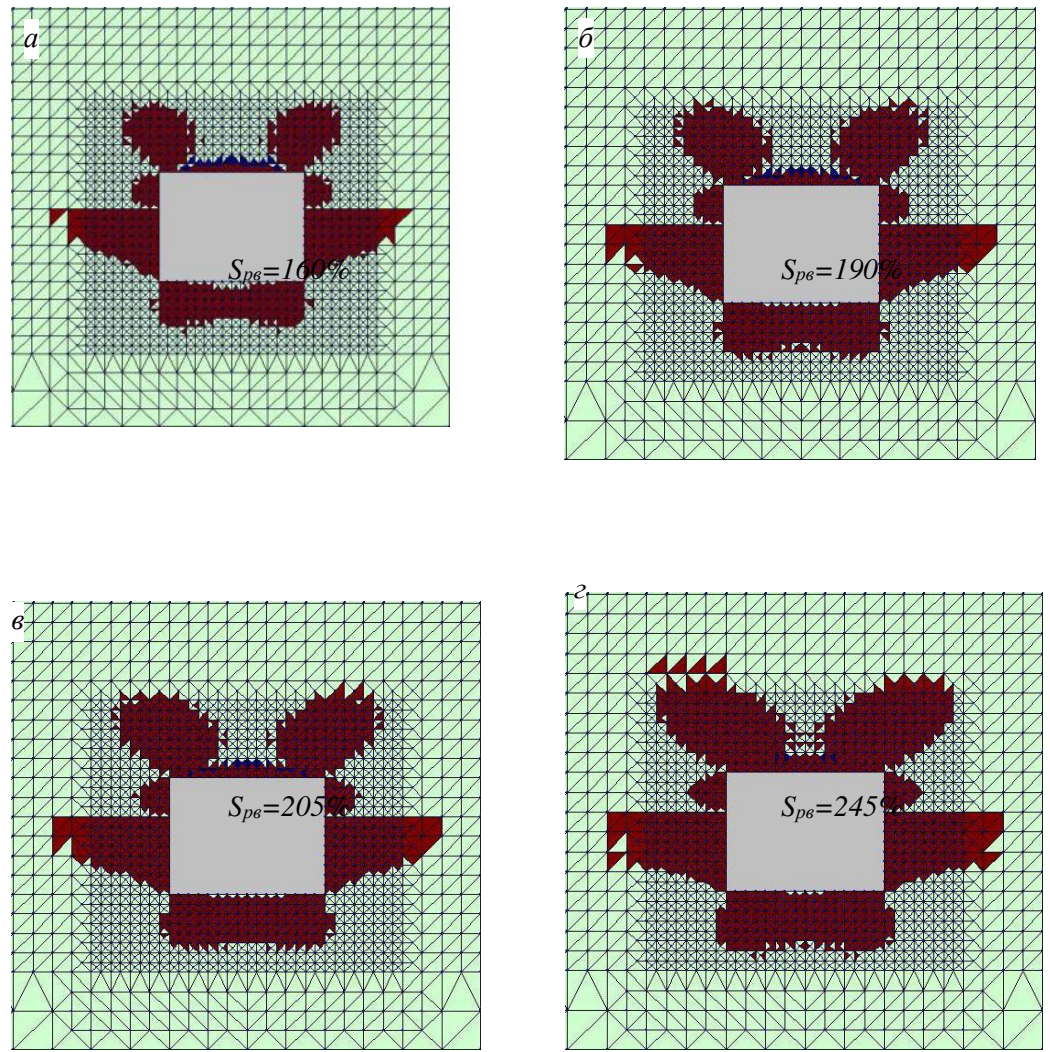

$$
\begin{aligned}
& \text { - tensile stress fracture; } \\
& \text { - compressive stress fracture; } \\
& - \text { undestructed elements }
\end{aligned}
$$

Fig. 3. The configurations of rock destruction zones around a mine working with hard-to-collapse roof in the zone of influence of longwall face during compaction of the destroyed rocks and expansion of the lining at various distances from the longwall face line: $20 \mathrm{~m}(a), 10 \mathrm{~m}(b), 5 \mathrm{~m}(c), 0 \mathrm{~m}(d)$

With a hard-to-collapse roof in the zone of temporary abutment pressure, the relative area of the fracture zone on the longwall face line was $S_{p s}=2.45$, which is 1.01 times smaller than the size of the zone of inelastic deformations to produce under similar conditions. For an easily collapsible roof with a minimum cantilever length of 
suspended rocks, the decrease in the fracture zone on the face line due to compaction and lining action was $3 \%$. Therefore, it is inefficient (useless) to compact the destroyed rocks and the spacer support in the zone of temporary abutment pressure of the longwall face. It has practically no effect on the change in the size of the fracture zone around the mine working.

Table 1

Change in the area of the destruction zone around the mine working

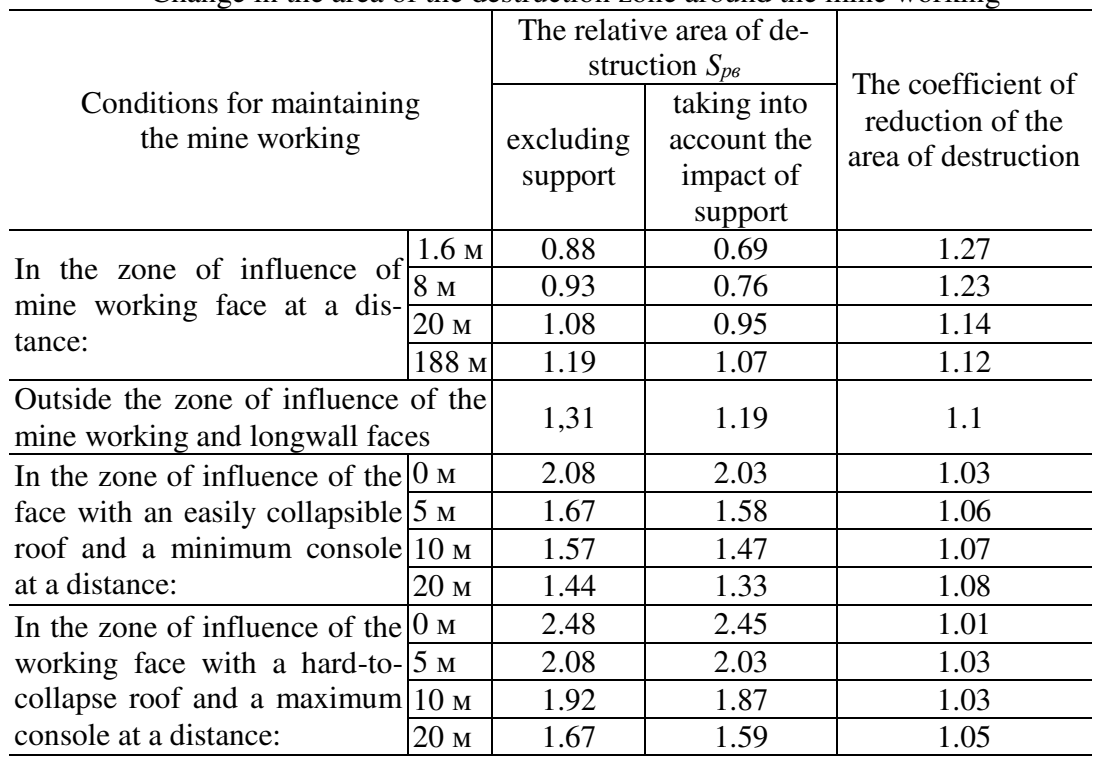

In the table 1 it is presented the results of calculating the relative area of destruction around the mine working for all options. The table shows that the maximum reduction in the area of destruction around the mine is achieved when installing spacers in near the face of the mine working. The effectiveness of compaction of rocks decreases as the distance from the face to the point of expansion of the support increases. It should be noted that the spacer of the support at a too small distance from the face does not provide effective compaction, since in this case the area of the fracture zone at the point of expansion of the support is small, which does not allow compaction of the destroyed rocks to a greater depth. 


\section{Conclusions}

Thus, controlling the rock pressure effects with the help of preliminary expansion of the support frames and compaction of the destroyed rocks in roof of mine working near its face makes it possible to reduce the area of the inelastic deformation zone in the impact zone of the longwall. When the support is spread at an optimal distance, depending on the deformation-strength properties of the rocks and the initial stress state of the rock mass, the effectiveness of compaction of the destroyed rocks is much higher, which allows you to assign rational support parameters.

The above methods of prediction of rock pressure effects were used to develop recommendations for improving the reliability of the 9 th western conveyor incline of the $l_{6}$ layer of the coal mine "Mashchinskaya".

During the 9th western conveyor incline construction, the displacements of the roof rocks according to the prediction technique were $181 \mathrm{~mm}$, which is consistent with the results of displacement measurements using depth benchmarks $(168 \mathrm{~mm})$. Taking into account the subsidence of the roof, in the reference pressure zone in front of the first longwall face, during the reuse period behind the first and in the abutment pressure zone in front of the second longwall, determined in accordance with the standard [9], the total rock displacements the roofs will be $1267 \mathrm{~mm}$, which exceeds the constructive compliance of even a five-link arched support and necessitates a double undermining of the soil (in the pressure zones in front of the first and second longwall faces).

Recommendations for improving the reliability of the 9th west conveyor incline provide for the use of a trapezoid support of increased bearing capacity (КПС) from СВП-27 with straight racks instead of a three-link arched support, and installation of the frames of this support with a spacer, carried out with the help of two hydraulic racks 2СУГ 30 installed under the top, which corresponds to a sealing force of $560 \mathrm{kN}$. Using computer simulation the distance from the face is optimized, at which the lining spacing is carried out $(28 \mathrm{~m})$ and which corresponds to the minimum displacements of the roof (89 $\mathrm{mm}$, which 2.03 times less than the base version). As a result of the expansion, compaction of the roof rocks has been achieved, due to which their total displacements over the entire service life of the mine 
working have been reduced to $677 \mathrm{~mm}$, which corresponds to the constructive compliance of the trapezoidal support $(700 \mathrm{~mm})$. The cross-sectional area of the mine working when fastened with a КПС support $S_{c b}=11.4 \mathrm{~m}^{2}$, which is smaller compared to the arched shape with the same width. The load on the lining, determined according to the standard [9], is $208 \mathrm{kN}$, and the density of the lining with its working resistance of $240 \mathrm{kN}$ is $1.0 \mathrm{frame} / \mathrm{m}$. The economic effect of the introduction of recommendations for the entire service life of the development is 2987.9 thousand UAH (roughly 100 thousand $€$ ).

References

1. Bulat A.F., Kurnosov A.T. (1987) Upravleniye geomekhanicheskimi protsessami pri otrabotke ugol'nykh plastov. Kyiv, Ukraine : Naukova dumka.

2. Zienkewitz O., Chang M. (1974) Metod konechnykh elementov v teorii sooruzheniy i mekhanike sploshnykh sred. Moscow, Russian Federation : Nedra.

3. Gorodetsky A.S., Evzerov I.D., Melnikov S.L. (1997) Rukovodstvo pol'zovatelya programmnym kompleksom «Lira-Windows». Kyiv, Ukraine : Goskomstroy.

4. Gorodetsky A.S., Shmukler V.S., Bondarev A.V. (2003) Informatsionnyye tekhnologii rascheta i proyektirovaniya stroitel'nykh konstruktsiy. Kharkov, Ukraine : NTU "KhPI".

5. Babiyuk G.V., Didenko M.A. (2008) Funktsiya vliyaniya zaboya vyrabotki na napryazhenno-deformirovannoye sostoyaniye massiva. Vestnik MANEB, 4, 19-23.

6. Babiyuk, G.V., Babiyuk, G.G., Toptun, N.I. (2001). Patent of Ukraine No. 35719 A. Retrieved from http://uapatents.com/7-35719-sposib-montazhuramnogo-piddatlivogo-kriplennya.html?do=download

7. Babiyuk, G.V., Babiyuk, G.G., Toptun, N.I. (2000). Montazh ramnoy podatlivoy krepi s predvaritel'nym rasporom. Ugol' Ukrainy, 4, 21-24.

8. Babiyuk G.V., Didenko M.A. (2005) Modelirovaniye deformatsionnykh protsessov vokrug provodimoy vyrabotki pri aktivnom vozdeystvii krepi na porodnyy massiv. Razrabotka rudnykh mestorozhdeniy : resp. nauchno-tekhnicheskiy sbornik, 89, 108-112.

9. SOU 10.1.00185790.011 (2007) Pidhotovchi vyrobky na polohykh plastakh. Vybir kriplennya, sposobiv i zasobiv okhorony. Kyiv, Ukraine. 